\title{
Cross-Sectional Absolute Deviation Approach for Testing the Herd Behavior Theory: The Case of the ASE Index
}

\author{
Imad Zeyad Ramadan ${ }^{1}$ \\ ${ }^{1}$ Department of Finance, Applied Science University, Amman, Jordan \\ Correspondence: Imad Zeyad Ramadan, Associate Prof., Department of Finance, Applied Science University, \\ P.O. Box 166, Amman, Jordan. E-mail: i_ramadan@asu.edu.jo
}

Received: December 24, 2014

Accepted: January 1, 2015

Online Published: February 25, 2015

doi:10.5539/ijef.v7n3p188

URL: http://dx.doi.org/10.5539/ijef.v7n3p188

\begin{abstract}
This study aimed to test whether the herd behavior appears in the Amman Stock Exchange (ASE). Using data on a daily basis for a sample of companies in the Free Float Share Weighted Index during the study period from the beginning of the, 2000 to the end of August 2014 and using the Cross-Sectional Absolute Deviation (CSAD) Approach. The results found that the non-linear relationship between the cross sectional absolute deviation of the stock returns and the return of the market portfolio is an inverse relationship $\left(\gamma_{3}=-0.179\right)$, so that the dispersion decreases with the increase in market rate of return, which means that investors during the study period were emulating the performance of the market without paying attention to the stock's characteristics regarding risk and return, which suggests that investors are taking the herd behavior.
\end{abstract}

Keyword: financial behavior, herd behavior, Amman Stock Exchange

\section{Introduction}

Understanding investors' behavior in stock exchange was a significant challenge faced by researchers and practitioners. Many searches have concluded that rationality concept and Efficient Market Hypothesis (EMH) are still suffering key deficiencies in stocks revenues models practically. Many researchers have attributed collapses of stock exchange in many countries to human feelings instead of rational thinking. Efficient Market Hypothesis $(\mathrm{EMH})$, one of investment hypotheses, states that it is impossible to "beat the market" because Efficient Market leads to make the current stocks reflect all information that affects prices. According to Efficient Market Hypothesis (EMH) stocks are always traded in market in their fair prices, what makes it's possible to buy or sell stocks at prices lower or higher than stocks' fair prices. Accordingly, it is impossible to beat the market through market's experts or timing, and the only way to have higher revenue shall be through the investment in high risk investments. However, the rational assumptions, which support the Efficient Market Hypothesis (EMH), often conflicts practically with the herd behavior that is evident in many of the capital markets. According to (Bikchandani \& Sharma, 2000) herd behavior describes a group of individuals who imitate others' decisions with no interest in their own beliefs. During herd behavior, the investors ignore their own beliefs and just imitate market's expectations. This behavior has a significant effect on securities prices. Ten et al. (2008) stated that herd behavior may lead to deviation of stock prices from their fair value through the properties of securities primarily associated with earnings and risks.

Understanding herd behavior in stock exchange has received considerable attention by economists and investors in stock exchange. Since economists have concern in behavioral effect on stocks prices, due to this potential effect's impact on financial assets pricing and evaluation models, investors have concern with this behavior due to profits opportunities that could be achieved through the adoption of this behavior.

Herd behavior of investors in the capital markets has been studied dramatically in recent years. Experimental studies have focused primarily on the United States and the European and Asian markets. Many researches (Christie \& Huang, 1995; Chang et al., 2000; Gleason, Mathur, \& Peterson, 2004) has rejected the existence hypothesis of the herd behavior in the US stock market. In contrast, Demirer and Kutan, (2006) concluded that the lack of evidence to herd behavior in the Chinese Stock Market. Chiang et al. (2010) and Tan et al. (2008), have concluded significantly thatt the investors in China's stock market taking the herd behavior. Tessaromatis and Thomas, (2009) concluded that existence of evidence of herd behavior in the Athens Stock Market. Also Chiang and Zheng, (2010) and Khan et al. (2011), have concluded the existence of statistically significant 
evidence that herd behavior exists in number of developed European countries.

\section{Statement of Problem}

The problem of the study stems from the large discrepancies in the results of previous studies on the behavior of the herd, and the lack of studies of the herd behavior in the developing capital markets, and the Jordanian capital market specifically, Thus, the question that the study seeks to answer is: are investors in Amman Stock Exchange taking the herd behavior?

\section{Importance of the Study}

Because of the great interest in herd behavior by economists and investors in financial markets, this standard analytical study aimed to identify whether herd behavior appears in the developing capital markets, Amman Stock Exchange in particular. Thus: the importance of the current study stems from being addressing a subject of great importance of which is not agreed upon so far, it also explores the herd behavior in least developed stock exchange, particularly the Jordanian capital market.

\section{Theoretical Framework}

There are generally two points of view regarding the subject of investment behavior in stock exchange: traditional point of view, and Behavioral Finance point of view. Efficient Market Hypothesis is considered as the corner stone of the traditional framework of investment behavior. In fact, finance field was academically and theoretically built and adopted based on Efficient Market Hypothesis. Within an efficient market, Stock prices fully reflect all available information. Accordingly, investors cannot use investment strategies to beat the market over the long term. There are three levels of market efficiency: the Weak form, which assumes that the securities prices have reflected all historical information upon their occurrence, where such information become irrelative and do not currently affect the prices. The second level is the semi-strong form of efficiency, which assumes that the securities prices have reflected all available information. Finally, the Strong form of the efficiency, which assumes that the securities prices have reflected all relative information.

Efficient Market Hypothesis depends on Arbitrage Hypothesis and Rational behavior for investors. As for rational behavior, the behavior of all investors shall be rational, even if some investors' behaviors were irrational; the stock prices will not be affected by this behavior because investors' behaviors are random and will cancel each other. Even thought investors' behaviors were irrational and non-random, Arbitrage will eliminate the irrational behavior against prices, and due to the results of the numerous studies carried out at the Sixties and the Seventies of the last century which supported Efficient Market Hypothesis, this hypothesis made a hit theoretically and experimentally.

In the eighties of the last century, a group of experimental results which opposed the Efficient Market Hypothesis, such as the efficiency of stock prices, where many researchers concluded that the securities in which $(\mathrm{P} / \mathrm{E})$ ratio is high ,they are securities estimated at a value higher than their fair value and vice versa. Also, the effects of evaluation of the securities earnings were documented what contradicts Efficient Market Hypothesis.

In response to the anomalies in the behavior of some securities returns, and inability of the traditional models based on the Efficient Market Hypothesis to explain this anomaly, a new field in the area of finance and funding was emerged,which is a behavioral finance. This field is known as the Science funding from a broader viewpoint of social sciences, which includes both sociology and psychology. Nowadays, behavioral finance is considered as one of the most important areas of research which challenges and opposes the Efficient Market Hypothesis.

According to Boyer et al. (2006), Behavioral Finance depends on two foundations: Limited arbitrage and Psychology. They concluded that arbitrage practically accords with risks and costs, as a result, arbitrage cannot eliminate the problem of securities mispricing. This result contradicts with Efficient Market Hypothesis which significantly depends on arbitrage's ability to eliminate mispricing in stock exchange. As for Psychology, behavioral finance indicates that Psychology is able to provide a possible explanation for the collapse of financial markets and experimental puzzles incomprehensible through the efficient market hypothesis.

Most studies carried out on herd behavior in stock exchange were based on Christie and Huang (1995) and Chang et al. (2000) models, and the scientific basis on which these models were built was Capital Assets Pricing Model (CAPM), and through herd behavior, the investors align their rational beliefs in favor the collective decision in the market, and thus, stock returns tend towards market return, and as herd behavior is distinguished itself from Capital Assets Pricing Model (CAPM), this leads to the existence of a testable hypothesis that lies in the difference between stock return and market return. According to Gleason, Mathur, and Peterson (2004), Demirer and Kutan (2006) and Tan et al. (2008) herd behavior can be revealed through market volatility Cross 
Sectional Standard Deviation (CSSD). If investors trust market expectations and follow them, investors' return will not deviate from market return, whereas dispersion level or variance between individuals' return and market return, in light of adopting herd behavior by investors, will be zero. When stock return differs from market return, dispersion increases, and in case investors follow market's expectations, dispersion will become significantly less than the mean.

$$
C S S D_{i, t}=\sqrt{\frac{\sum_{i=l}^{N}\left(R_{i, t}-R_{m, t}\right)}{N-1}}
$$

Where: CSSD is the Cross Sectional Standard Deviation for $i^{\text {th }}$ firm on $t^{\text {th }}$ period and expresses the dispersion. $R_{i, t}$ is the return of the $i^{\text {th }}$ firm on $t^{\text {th }}$ period. $R_{m, t}$ is the average of the cross sectional return of the market portfolio consisting of $\mathrm{N}$ shares during the $t^{\text {th }}$ period.

According to Gleason, Mathur, and Peterson (2004) and Henker, Henker and Mitsios (2004), dispersion measures the extent to which investors follow market's expectations (degree of herd behavior), and accordingly, if investors adopt herd behavior, we expect return dispersion to be less than the mean.

According to Christie and Huang (1995) testing herd behavior using dispersion depends on considering the study of fluctuations in the immoderate values of the market rates in order to reveal dispersion degree which is usually locates at the end of the return distribution curve's edge, and accordingly we examine if dispersion degree differs with statistical significance from mean of dispersion through the following regression equation:

$$
C S S D_{t}=\alpha+\beta_{1} D_{t}^{U}+\beta_{2} D_{t}^{L}+\varepsilon_{t}
$$

Where: $C S A D_{i t}$ is the Cross Sectional standard Deviation for $i^{\text {th }}$ firm on $t^{\text {th }}$ period and expresses the dispersion. $D$ is the dummy variables. $\beta^{s}$ the coefficient to be estimated.

It is expected that dummy variables can reveal herd behavior whereas the negative value of $\beta^{s}$ indicates that herd behavior is existed, while the positive values indicate that the non-existence of herd behavior among investors. According to Henker, Henker and Mitsios, (2004) immoderate values were defined as the 5\% of values existed in the distribution curve's parts, and these values were excluded.

One important defect of Cross-Sectional Standard Deviation (CSSD) approach used for expressing dispersion degree is the assumption that the relation between the dispersion in stock returns and market portfolio return is a linear relation as the change values in stock returns dispersion has a same change at the same value in market portfolio return. Chang and Zheng (2010) have suggested a new approach to examine herd behavior using CAPM model which is Cross-Sectional Absolute Deviation (CSAD). The main idea of this approach is that if the herd behavior becomes apparent among investors, the relationship between the cross-sectional deviation and market portfolio is a linear one, and this shall mean that Cross-Sectional Absolute Deviation (CSAD) will decrease or increase at least less than the relative rate of market return.

Consistent with Chang and Zheng, (2010) the CSAD will be measured as follows:

$$
C S A D_{i . t}=\frac{1}{N} \sum_{i=1}^{N}\left|R_{i, t}-R_{m, t}\right|
$$

Where: $C S A D_{i t}$ is the Cross Sectional Absolute Deviation for $i^{\text {th }}$ firm on $t^{\text {th }}$ period and expresses the dispersion. $R_{i, t}$ is the return of the $i^{\text {th }}$ firm on $t^{\text {th }}$ period. $R_{m, t}$ is the average of the cross sectional return of the market portfolio consisting of $\mathrm{N}$ shares during the $t^{\text {th }}$ period.

In order to detect the behavior of the herd on the market level, the regression equation that will be estimated will be as follows:

$$
C S A D_{i, t}=\gamma_{0}+\gamma_{1} R_{m, t}+\gamma_{2}\left|R_{m, t}\right|+\gamma_{3} R_{m, t}^{2}+\varepsilon_{i, t}
$$

Where: CSAD is the Cross Sectional Absolute Deviation for $i^{\text {th }}$ firm on $t^{\text {th }}$ period and expresses the dispersion. $R_{m, t}$ is the average of the cross sectional return of the market portfolio consisting of $\mathrm{N}$ shares during the $t^{\text {th }}$ period. $\left|R_{m, t}\right|$ is the absolute value of the average of the cross sectional return of the market portfolio consisting of $\mathrm{N}$ shares during the $t^{\text {th }}$ period.

It is worth mentioning that model Chang et al. (2000) was adjusted by adding $R_{m, t}$ to the right part of the Equation (4) in order to overcome the randomness of investors' behavior during different market conditions. Also, since herd behavior usually appears significantly during the high market's movement, the existence of the behavior was selected via the linear relationship between Cross-Sectional Absolute Deviation (CSAD) and the mean of market portfolio cross-sectional return, and this is applied by adding the variable $R_{m, t}^{2}$.

As previously mentioned, if change in CSAD was less than the average of market portfolio return, where the 
value of regression coefficient $\gamma_{3}$ was negative and statistically significant, this shall mean that there is statistically significant evidences on that investors are following herd behavior.

\section{Hypothesis}

From the above the hypothesis that the study seeks to test can be formulated the as follows:

$H_{0}$ : The value of the dispersion between investors return and return on the market portfolio is statistically significantly greater than or equal to the average return of the market portfolio at the level of $\alpha=0.05$.

The null hypothesis can be reformulated mathematically as follows:

$$
H_{0}: \gamma_{3} \geq 0, \mid \alpha<0.05
$$

Where: $H_{0}$ is the null hypothesis $\gamma_{3}$ regression coefficient to be estimated in equation (4).

\section{Data and Variables of the Study}

Christie and Huang (1995) has indicated that herd behavior is usually a short-term phenomenon, and can be observed only during frequent data. Also Ten et al. (2008) have concluded that herd behavior becomes more apparent when using data on daily, monthly and annually basis. Accordingly, and in line with the previous studies data of Free Float Share Weighted Index used in Amman Stock Exchange were applied, and which consists of 100 companies during the period January, 2000 to August, 31, 2014 on daily basis resulting in 3789 year firm observation. Return can be computing based on the following equation:

$$
R_{t}=\log \frac{P_{t}-P_{t-1}}{P_{t-1}}
$$

Where: $R_{t}$ is the Return during the period $t . P$ closing share price or index value.

All data used in this study were obtained through the official website of Amman Stock Exchange (ASE).

\section{The Empirical Results}

\subsection{Descriptive Analysis}

Table 1 shows the results of the descriptive analysis of study sample's data consisting of 100 company within the sample of the Free Float Share Weighted Index. The table shows that the companies within the sample have achieved an average return of 0.019 during the year of the study. Decline in return is attributed to the loss the market faced as a result of the financial crisis, and this is significantly apparent through the lower value of return during the period under study which shows loss value of (-3.223).

Table 1. The results of descriptive statistical analysis of the daily return

\begin{tabular}{cc}
\hline Mean & 0.019 \\
\hline Standard Deviation & 0.7472 \\
Minimum & -3.223 \\
Maximum & 2.1440 \\
Skewness & 1.237 \\
Kurtosis & 11.917 \\
Jarque-Bera & 9514.48 \\
p-value & 0.000 \\
Observations & 3789 \\
\hline
\end{tabular}

Table 1 shows skewness in data, and that data suffer kurtosis where kurtosis coefficient was greater than 3 , what in terns makes us reject the assumption of normal distribution of the data, and thus, the linear relationship between stock return dispersion and market return dispersion, what assures the preference of CSAD over CSSD to address and study herd behavior.

\subsection{Regression Analysis}

Equation (4) was estimated to examine whether the investors in Amman Stock Exchange follow herd behavior or not. As previously mentioned, the statistically significant negative value of the regression coefficient of the variable $R_{m, t}^{2}$ indicates the existence of herd behavior. Table 2 shows the results of Cross-Sectional Absolute Deviation (CSAD) based on equation (4). 
Table 2. The results of the regression analysis for CSAD depending on the equation 4

\begin{tabular}{cc}
\hline$\gamma_{0}$ & $0.473^{* *}$ \\
& $(59.384)$ \\
\hline$\gamma_{1}$ & -0.097 \\
& $(-0.938)$ \\
$\gamma_{2}$ & $0.339^{* *}$ \\
& $(14.052)$ \\
$\gamma_{3}$ & $-0.179^{* *}$ \\
& $(-9.378)$ \\
Adjusted $R^{2}$ & 0.301 \\
F-statistic & 159.854 \\
p-value & 0.000 \\
$\mathrm{~N}$ & 3789 \\
\hline
\end{tabular}

Note. The figures in brackets is the value of a statistical test t. ** Statistically significant at the $1 \%$ level of significance.

The results of analysis at Table 2 show that the value of $\gamma_{3}$ has a negative value that differs from zero at the significance level 0.01, what means that during the time period of the study, the investors in Amman Stock Exchange were following the market's performance with no interest in stock's properties in term of risks and return.

Accordingly, we do refuse the null hypothesis that states the non- existence of herd behavior during the time period of the study in Amman Stock Exchange, what confirms the existence of herd behavior in Amman Stock Exchange.

\section{Conclusion}

The current study aimed to identify whether herd behavior is adopted in Amman Stock Exchange or not. Using Free Float Share Weighted Index used in Amman Stock Exchange during the period January 2000 to August 31, 2014, and $t$ using the Cross-Sectional Absolute Deviation (CSAD) Approach, the current study showed that the non-linear relation between the Cross-Sectional Absolute Deviation of stock returns and market return was an inverse relationship $\left(\gamma_{3}=-0.179\right)$ where dispersion decreases while market return increases, which means that investors in Amman Stock Exchange were following the market's performance with no interest in stock's properties in term of risks and return.

The current study contributed to provide new evidences regarding investors' behavior in developing countries, particularly Jordan. As far as the researcher knows, this is the first study that examines the herd behavior in Amman Stock Exchange, and thus, the results of the current study are considered as a new addition to the previous experimental studies.

\section{Acknowledgements}

The author is grateful to the Applied Science Private University, Amman, Jordan, for the financial support granted to this research project (Grant No. DRGS -2013- 2014 - 52).

\section{References}

Bikhchandani, S., \& Sunil., S. (2000). Herd Behavior in Financial Markets. IMF Working Paper WP/00/48.

Boyer, B. H., Kumagai, T., \& Yuan, K. (2006). How Do Crises Spread? Evidence from Accessible and Inaccessible Stock Indices. The Journal of Finance, 61(2), 957-1003. http://dx.doi.org/10.1111/j.1540-6261.2006.00860.x

Chang, E. C., Cheng, J. W., \& Khorana, A. (2000). An examination of herd behavior in equity markets: An international perspective. Journal of Banking and Finance, 24(10), 1651-1679. http://dx.doi.org/10.1016/S0378-4266(99)00096-5

Chiang, T. C., \& Zheng, D. (2010). An empirical analysis of herd behavior in global stock markets. Journal of Banking and Finance, 34(8), 1911-1921. http://dx.doi.org/10.1016/j.jbankfin.2009.12.014

Chiang, T. C., Li, J., \& Tan, L. (2010). Empirical investigation of herding behavior in Chinese stock markets: Evidence from quantile regression analysis. Global Finance Journal, 21(1), 111-124. http://dx.doi.org/10.1016/j.gfj.2010.03.005

Christie, W. G., \& Huang, R. D. (1995). Following the Pied Piper: Do Individual Returns Herd around the 
Market? Financial Analysts Journal, 51(4), 31-37. http://dx.doi.org/10.2469/faj.v51.n4.1918

Demirer, R., \& Kutan, A. M. (2006). Does herding behavior exist in Chinese stock markets? Journal of International Financial Markets, Institutions \& Money, 16(2), 123-142. http://dx.doi.org/10.1016/j.intfin.2005.01.002

Gleason, K. C., Mathur, I., \& Peterson, M. A. (2004). Analysis of intraday herding behavior among the sector ETFs. Journal of Empirical Finance, 11(5), 681-694. http://dx.doi.org/10.1016/j.jempfin.2003.06.003

Henker, J., Henker, T., \& Mitsios, A. (2004). Do Investors Herd Intraday in Australian Equities? International Journal of Managerial Finance, 2(3), 196-219. http://dx.doi.org/10.1108/17439130610676475

Khan, H., Hassairi, S. A., \& Viviani, J. L. (2011). Herd Behavior and Market Stress: The Case of Four European Countries. International Business Research, 4(3), 53. http://dx.doi.org/10.5539/ibr.v4n3p53

Tan, L., Chiang, T. C., Mason, J. R., \& Nelling, E. (2008). Herding behavior in Chinese stock markets: An examination of A and B shares. Pacific-Basin Finance Journal, 16(1), 61-77. http://dx.doi.org/10.1016/j.pacfin.2007.04.004

Tessaromatis, N., \& Thomas, V. (2009). Herding Behavior in the Athens Stock Exchange. Investment Management and Financial Innovations, 6(3), 156-164.

\section{Copyrights}

Copyright for this article is retained by the author(s), with first publication rights granted to the journal.

This is an open-access article distributed under the terms and conditions of the Creative Commons Attribution license (http://creativecommons.org/licenses/by/3.0/). 